\title{
Effectiveness of a multi-device 3D virtual environment application to train car service maintenance procedures
}

\author{
Simone Borsci ${ }^{1}$, Glyn Lawson ${ }^{1}$, Bhavna Jha ${ }^{2}$, Mark Burges ${ }^{3}$, Davide Salanitri ${ }^{1}$
}

1- Human Factors Research Group, Faculty of Engineering, The University of Nottingham, Nottingham NG7 2RD, United Kingdom

2- Jaguar Land Rover, Abbey Road, Whitley, Coventry, CV3 4LF, United Kingdom. e-mail: bjha1@jaguarlandrover.com

3- Holovis International Ltd, Lutterworth, UK

\begin{abstract}
This paper reports a study which demonstrates the advantages of using virtual-reality based systems for training automotive assembly tasks. Sixty participants were randomly assigned to one of the following three training experience to learn a car service procedure: i) observational training through video instruction; ii) an experiential virtual training and trial in a CAVE; and iii) an experiential virtual training and trial through a portable 3D interactive table. Results show that virtual trained participants, after the training, can remember significantly better $(p<.05)$ the correct execution of the steps compared to video-trained trainees. No significant differences were identified between the experiential groups neither in terms of post-training performances nor in terms of proficiency, despite differences in the interaction devices. The relevance of the outcomes for the automotive fields and for the designers of virtual training applications are discussed in light of the outcomes, particularly that virtual training experienced through a portable device such as the interactive table can be effective, as can training performed in a CAVE. This suggests the possibility for automotive industries to invest in advanced portable hardware to deliver effectively long-distance programmes of training for car service operators placed all over the world.
\end{abstract}

Keywords: Automotive, Effectiveness of training, Virtual reality, Usability, Turst.

\section{Introduction}

Nowadays Computer-Based Training applications are commonly used in different fields - e.g., surgery, education, military - to train specialists and operators' skills (Corvaglia 2004; Mantovani 2003). Computer-Based training applications are often experienced in virtual reality (VR) 3D environments to allow trainees to experience the training contents in an immersive world in which virtual versions of real objects, contexts, tools and actions can be simulated and experienced by operators (Haque and Srinivasan 2006; Kothari et al. 2002; Watterson et al. 2002).

VR systems, defined as human-computer environments in which users are immersed in, and able to perceive, act and interact with a 3D world (Bowman et al. 2002; Milgram and Kishino 1994), are considered powerful and reliable (Mantovani 2003) tools to train the skills of employees, specialists and managers - e.g., prototype and assembly, drive, fight, fly, surgery procedures (Belardinelli et al. 2008). Moreover, these Virtual-Based Training (VBT) software solutions are applied in training programme to simulate controlled environments of learning in which professionals may: i) acquire, or increase their previous procedural skills - i.e., the necessary know-how to perform effectively and efficiently a procedure (Anderson 1982) - and, ii) exercise the skills associated to their work - such as abstract reasoning, visualization and management of complex information spaces

(Salzman et al. 1999). 
Automotive industries have been pioneers in the use of 3D environments for prototyping and evaluating a product's design (Gomes de Sá and Zachmann 1999). In line with this, today automakers are exploring, with growing interest, the use of VBT solutions for training operators (e.g., see: Malmsköld et al. 2014) by concurrently investing in international research projects - see for instance: European projects SKILLS - http://www.skills-ip.eu/; and VISTRA - http://www.vistra-project.eu.

As Malmsköld and colleagues (2014) well underline in literature there are several evidences of a positive impact of VBT for training operators' skills in manufacturing such as: welding (Fast et al. 2004; Mavrikios et al. 2006), machining, prototyping, inspecting (Mujber et al. 2004), and object assembly (Stork et al. 2012; Webel et al. 2013). Nevertheless, only a few studies are available in the literature about training professionals such as service operators who work away from the production line (e.g., Anastassova and Burkhardt 2009; Anastassova et al. 2005), and to date no studies investigate the effectiveness of virtual tools for training car service maintenance procedures.

Car service maintenance is a key topic for automotive industries as service operators are the main interface between the brand and customers with car issues (Dombrowski et al. 2011; Gaiardelli et al. 2014). Therefore, for manufactures a main objective is to invest in effective tools to enhance service operators' procedural skills.

Different to assembly line operators, or professionals who work on machine repair at manufacturing centres, car service operators, based all over the world, have to be trained to perform a large set of variable procedures on one of the most customised product in the market (Parry et al. 2011). For instance, a luxury model of car can have up to $10^{24}$ possible configurations - e.g., different engine, chassis, electronic configurations. Consequently, an operator who has to change the same fault component on two customized cars could face different procedures, as well as different disassembly and reassembly steps.

To properly support professionals of car service, automotive industries continuously invest in the development of the training programmes for novice and experts operators, as well as in new methods and tools to quickly update the skills of technicians all over the world when new or amended procedures of car service are available. Nevertheless, in literature there is no empirical evidence that VBT applications are effective tools to drive operators to learn a car service procedure i.e., disassembly and changing a faulty component and to perform proficiently the acquired procedure i.e. correctly and within a time limit.

\section{Current practices of car service operators' training: experiential and observational training}

As practitioners underline (Anastassova and Burkhardt 2009; Anastassova et al. 2005) training programmes in manufacturing and service are usually based on learning-by-doing approaches (i.e., experiential learning, see: Kolb 1984) in which training content is delivered: i) at local training centres where trainees, after a theoretical course, can observe experts making the procedure and try to apply the new skills during simulations on real cars; or ii) 'on-the-job', where experts/trained professionals explain new procedures to untrained colleagues. This kind of experiential approach, in which theory and practice are mixed together, is considered the most effective for training operators' procedural skills (Anastassova and Burkhardt 2009; Anastassova et al. 2005; Seymour et al. 2002; Stork et al. 2012; Webel et al. 2013; Yuviler-Gavish et al. 2013). Nevertheless experiential training is not always a cost-effective solution for two main reasons. First, learning-by-doing activities can be performed only when a real car can be shown to trainees and operators can interact with it. However in some cases there are risks associated with training people on real products. For instance, i) to operate on a real car could be dangerous for naïve operators even when they are supervised, ii) the use of real car for training disassembly and reassembly process could seriously compromise car integrity, moreover, iii) for industrial sensitivity reasons, a new model of car is closely guarded, even from 
trainers and service operators until launch. Thus, when operators are trained on service procedures for new vehicles, they often receive mostly theoretical training with a limited access to the new model car. Second, to set up experiential training for operators around the world requires time, and today due to the competitiveness of the automotive field, auto-makers more often have to quickly recall and update operators on new or modified car maintenance procedures. Therefore, to speed the update of operators' know-how manufacturers are used to deliver training contents with minimal experiential activities. In fact, to overcome the issues associated with setting-up a training programme with experiential activities, automotive companies deliver training contents and updates through tools such as: web repositories with video and textual manuals, virtual rooms, chat, and web and mobile apps (Alippi, de Russis, \& Piuri, 2003; Anastassova \& Burkhardt, 2009). These long-distance training tools allow operators to acquire training contents through observational activities - i.e., learning-byobserving (Bandura 1992) video, manual and theoretical explanations of the procedure.

Training programmes based only on observational activities are quicker in terms of content diffusion, and less expensive than courses with learning-by-doing activities, however, as well-known in literature the lack of experiential activities associated to the observation could potentially reduce the overall impact of training (Bruner 1966; Kolb 1984; Renkl 2014).

The competitiveness and the globalization of the automotive market has created a conflict between the needs of manufacturers to speed the diffusion of training contents to trainees, and those of operators to interact with a product to effectively learn procedures (Ottosson 2002; Valdez et al. 2013). Research underlines that the most reliable way to balance the needs of manufacturers and operators is the development of VBT applications to support virtual learning-by-doing activities performed by operators at their service centres (Mantovani 2003; Mantovani et al. 2003; Mikropoulos et al. 1997). In fact, for the specific case of automotive field VBT applications remove the risks associated with interaction with a real car - i.e., safety of naïve operators, and real car integrity. Moreover, through VBT applications trainees may easily access and interact virtually with parts of new model cars.

As observed in literature, VBT applications offer to manufactures at least three main advantages. First, after the initial investment on the development of the system, VBT tools reduce the overall training costs and the time to diffuse the contents (Mantovani 2003; Mantovani et al. 2003). Second, VBT tools can be easily adapted and personalized to the people's needs and learning style by increasing the trainees' motivation during the training (Eugenia et al. ; Stork et al. 2012). Finally, practitioners and trainers by VBT systems can collect through the VBT application a wide set of data about the trainees' performances, to check, assess and calibrate the training process.

Manufacturers are used to developing their own internal VBT applications, and rarely are industries open to share their internal technological solutions; therefore, it is hard for experts to perform comparative analyses of the effectiveness of VBT applications for training operators in industrial fields (Mantovani 2003; Mantovani et al. 2003). In line with that, although the community of virtual reality experts agree on the positive effect of VBT tools, researchers often underline that the debate on the impact of these tools on the training of professionals' know-how is still open. In line with Borsci, Lawson and Broome (2015b), at least five main shortfalls in the research of virtual reality applied as a training tool in industry can be identified as follows:

i) Researchers commonly test VBT tools with small samples and with a limited set of evaluation criteria (Haque and Srinivasan 2006; Yuviler-Gavish et al. 2013).

ii) There is a gap in the literature among the experimental analyses of training for specialists (e.g., surgery) and industrial operators (Borsci et al. 2015b). In specialist training people's performances were tested through several standardized indexes to check the level of proficiency reached by trainees. Conversely, in industrial fields effectiveness were mainly assessed only by measuring the number of errors, and the time spent by operators to perform the procedure (Tang 
et al. 2003; Webel et al. 2013; Yuviler-Gavish et al. 2013; Yuviler-Gavish et al. 2011a).

Moreover, researchers rarely measured the proficiency reached by trainees after the training consistently (Ahlberg et al. 2007).

iii) Researchers in industry are mainly focused on proving the effectiveness and the quality of the VBT system but rarely gathered data through standardized tools on those personal factors which could affect people acquisition of the skills - e.g., visuospatial abilities of trainees (Ahlberg et al. 2007; Garg et al. 2002; Parsons et al. 2004), learning styles (Ai-Lim Lee et al. 2010), and the levels of expectations and trust in the use of tools (Mcknight et al. 2011). Moreover, researchers largely applied qualitative surveys to measure the perceived usability - i.e., satisfaction in use - of VBT application (Mantovani 2003). However usability is well-defined concept (ISO 9241-11, 1998) and several reliable and standardized questionnaires are available to assess the satisfaction in the use of a system. Concurrently, some evidence (Cabral et al. 2005; Flavián et al. 2006; Salanitri et al. 2015) underlines that trust in use and usability could be related, nevertheless in VBT literature this relationship was an unexplored issue. Finally, factors which could affect the safety in the used such as the cybersickness - intended as a syndrome induced by immersive systems (Sharples et al. 2008) - or the effectiveness of the training, such as the perceived workload are left uncontrolled in empirical experiments on virtual training for manufacturing and service operations.

iv) Comparative studies among virtual and non-virtual approaches to effectively transfer to operators a set of procedural skills are available in surgery literature (e.g., Seymour et al. 2002). Nevertheless, in industrial fields, researchers have mostly focussed their attention on the advantages of the VBT applications without comparing the effectiveness of these systems to other kind of approaches - e.g., video training.

v) The portability of training devices is a key, but unexplored, topic in virtual training for car service operators. Some researchers have tested augmented reality solutions, intended as extremely portable support by which operators, during a service, could receive instructions and enhanced information to perform better the operations on real cars (Anastassova and Burkhardt 2009; Tang et al. 2003). In line with that, augmented reality tools are a valuable solution to enhance the performance of operators but these applications are not developed to deliver virtual training programmes. Currently in the industrial literature there are no studies which have empirically analysed and compared portable versions of a VBT system in which operators can be fully trained on a car service operation in a virtual environment - e.g., 3D virtual interactive training experienced through PC desktop, 3D tablet, oculus rift and CAVE. The portability of a training system and the comparability between the effectiveness of training delivered through a portable device and an immersive system such as a CAVE is a hot topic in the industrial application of virtual reality.

The preceding discussion suggests that training with virtual applications is still an ongoing area of research, especially in specialised fields such as car service maintenance in which there is a lack of comparative assessment of VBT application effectiveness. Given this lack of comparative analysis the aims of this paper is two-fold.

The first aim is to compare the trainees' abilities to recover competences after observational training and VBT. In particular the VBT content will be delivered through a new software application experienced by trainees using two different devices: an immersive 4-sided CAVE or an interactive 3D holographic table - i.e., zSpace, see: www.zspace.com.The analysis of the three groups, one of which receives a video training and two of which received a virtual one will be used to compare the effectiveness of the training programmes - i.e., observational vs. virtual experiential. 
The second aim is to empirically analyse the ability of operators, after the virtual training with the new VBT tool, to perform a car service procedure effectively - i.e., correctly and within a proficiency time. The difference between the performances of two groups of participants trained by the VBT application was analysed to observe whether the interaction with the same VBT tool experienced through different devices affects people's acquisition of competences. Moreover, to observe the factors which could affect a virtual training on car service operations, we will explore the effect on people's performances after the training of the following factors which could affect the acquisition of the procedural skills in a VBT application: personal characteristics (i.e., age, education, experience, sex, the learning style and mental rotation), the perceived cognitive workload, the usability and the trust (and their relationship) and the cybersickness.

\section{Description of the Virtual Based Training (VBT) tool}

The VBT prototype application applied in this study was developed by HoloVis international, as part of the Live Augmented Reality Training Experience project (LARTE project, TSB - 101509).

LARTE-VBT tool is based on HoloVis game engine ( $\left.\mathrm{InMo}^{\mathrm{TM}}\right)$, which enables end-users to visualise and interact with CAD data by using a number of supported devices (see Fig. 1): multi-sided CAVE, powerwall, Oculus Rift, and interactive table-top displays.

\section{FIGURE 1 ABOUT HERE}

Differently from the other training applications usually designed by manufacturers for their specific internal use, LARTE-VBT was developed to be used by any industry which aims to arrange learningby-doing training for their professionals. For this study, the LARTE-VBT system was adapted to the specific requirements and needs of Jaguar Land Rover - JLR, partner of the LARTE project. The LARTE-VBT application was developed as an interactive 3D system in which people could receive an automatic (or a trainer-driven) step-by-step training to perform a procedure.

Several functions, included in the LARTE-VBT application, can be used by trainers of different industries to set up a virtual experiential activity. For the aim of this paper we report here only the following five main functions of this training application (Borsci et al. 2015c):

- Trainers can create a training by importing a CAD object, and setting a step-by-step training video of the procedure;

- Trainers can define a set of rules and relationships among the components of the 3D objects;

- Trainees can autonomously visualize each single step of the procedure by receiving in the virtual environment verbal and textual instructions of a service procedure, through a video recorded virtual explanation of the procedure;

- Trainees may manipulate the 3D car - e.g., rotate the whole CAD, assembly, disassembly, rotate and move any single components of the car, zoom in and out etc.

- Each trainee's interaction can be fully recorded and observed in the 3D environment.

\section{Methods}

Sixty volunteers (Male: 24; Age: 35.77, SD: 12.1) were recruited among professionals of JLR. The sample was composed by novice and intermediate technicians with similar expertise of car service operators - technician and trainers who are experts in machinery service, project management, inline operations, car service and design. Participants were stratified by their expertise, and they were randomly assigned to receive training on a car service procedure in one of the following groups:

i) VR1 - training with experiential learning of the procedure in a CAVE; 
ii) VR2 - training with experiential learning of the procedure through the zSpace;

iii) Control - training through a video explanation of the procedure.

One participant in each group was excluded for the following reasons: a participant of the group VR1 suffered cybersickness and quit the procedure, a participant of the group VR2 cannot visualise the third dimension and was excluded from the sample, a participant of the control group did not fully completed the post assessment activity. Finally each one of the three training groups was composed of 19 participants.

\subsection{Apparatus}

Participants of VR1 and VR2, respectively, experienced the learning-by-doing activities on:

- 4-sided CAVE (VR1) with rear-projected floor (Sony VPL-FE40) with a mirror rig and 2 projectors per wall -8 in total. The resolution of each projector was $1440 \times 1050$. The controller of the CAVE was an ART DTrack optical head and wand tracking. The tracking was integrated in a pair of lightweight polarized passive glasses. The system was run by 9 workstations.

- zSpace holographic 3D table (VR2) composed by a 24 in. (1920x1080) LCD monitor (tablet display) running at $120 \mathrm{~Hz}$. The controller was a laser-based wired six-degree-of-freedom stylus device. The tracking was integrated in a pair of lightweight polarized passive glasses (Noor and Aras 2015).

Participants who experienced a learning-by-observing training (i.e., control group) used a desktop computer with Microsoft (C) Windows 7 Enterprise, processor Intel @ core i7, 3.70 GHz, 8Gb of Ram, a dedicated graphic and sound system and a $19 \mathrm{in.} \mathrm{LCD} \mathrm{monitor.} \mathrm{Moreover,} \mathrm{these} \mathrm{participants} \mathrm{also}$ interacted, after the training, with a desktop 3D environment created by LEGO® - Digital Designer version 4.3 (LDD).

Moreover, an iPad mini with $16 \mathrm{~Gb}$ of RAM was used by trainers to show time and countdown to the users during the training, and the post training activities and to collect notes. Finally, a Sony HDD DCR-SR57 video camera was used to record the experiment.

\subsection{Target car service procedure}

A standard service procedure on a JLR model of car (Range Rover Evoque) was selected for the experiment. The procedure consists in disassembly and changing a fault lower arm of the front suspension of the car. The procedure was composed of a total number of 24 steps that people have to learn and perform to reach the goal. The main physical disassembly steps (such as remove and reinsert the components) were 8 . The remaining 16 steps were related to manipulative actions - i.e., rotate/move the car, change perspective, and localize the components.

The 3D version of the car, as well as the textual and video explanation of the procedure was provided by JLR. Participants received the same set of video, audio and textual instructions displayed in the virtual environment (groups VR1 and VR2) or through a video service performed by an expert on a real car (Control group).

\subsection{Experimental Procedure}

Participants of the control and virtual groups, experienced two different training modalities -i.e., Experiential and Observational, see Table 1). The observational group (i.e., control group) used a PC desktop to watch twice a video explanation of the procedure. The two experiential groups experience the same VBT software application, but VR 1 group received the training through a CAVE and VR 2 
groups received the training through the zSpace. Table 1 summarises the applied equipment (in terms of controllers and costs) and the different modalities of training.

\section{TABLE 1 ABOUT HERE}

Before the training, participants were invited to fill a set of pre-measures (see Table 1): i) a demographic survey; ii) a Mental Rotation Test (MRT, see: Peters et al. 1995) to assess their visuospatial abilities, and iii) a Kolb Learning Style Inventory (KLSI, version 4, see: Kolb and Kolb 2005a; Kolb and Kolb 2005b; Kolb 1984). In the training phase, participants of the control group were only requested to look carefully at the video explanation of the procedure twice, and to remember the correct order of execution of all the steps of the procedure. After the video explanation, participants were involved in a post-training activity of 10 minutes unrelated to the target car service procedure. In the 'post-training activity' (see Table 1), trainers instructed participants for 5 minutes in the use of the LDD tool through a PC desktop, and participants were requested to freely interact with a 3D model of $\mathrm{LEGO}{ }^{\circledR}$ technic car for 2 minutes, and to achieve a task of disassembly in 3 minutes i.e., remove the faulty engine from the LEGO ${ }^{\circledR}$ virtual model of car. Participants were assisted and supported by trainers all the time. When people could not accomplish the task in the LDD system within 3 minutes, trainers were instructed to help participants to finalize the procedure.

Differently from the control group, participants of the VR1 and VR2 groups were asked to fill a short symptom checklist (SSC, see: Sharples et al. 2008) to collect data about their cybersickness and the motion sickness before, during, and after the interaction with the system.

As showed in Table 1, the first step of the 'training on the target procedure' for VR1 and VR2 groups was the explanation to trainees of the use of controllers (for the CAVE, or the zSpace) and the main functions of the training system. The explanation of LARTE-VBT consisted of five tasks shown by trainers and performed by participants on a virtual model of car - i.e., different from the one of the target procedure: one exercise to zoom in and out, one in which people had to remove and reinsert a component of the car, two exercises of rotation of the whole car and car components, and one exercise to learn how to handle and move car components in the virtual space.

During the 'LARTE-VBT training' VR2 (see Table 1), participants received the virtual explanation of the procedure through the system and were then asked to perform each step of the procedure demonstrated automatically by the training system. Moreover, they were asked to perform a trial of the procedure. Each participant was requested to perform correctly the procedure, without a time limit. Participants were also informed that their performances were timed, but they were instructed, if they did not remember how to perform them, to ask to stop the time to look at the virtual explanation. Nevertheless, participants were allowed to look at the virtual explanation only after each 30 second interval. Moreover, participants were informed that at any time during the performance, whether they performed a mistake without solving it, the trainer could stop the time and force them to look at the virtual explanation of the procedure. Trainers were instructed to remind participants (when they showed some uncertainties) that they could stop the time and ask for the instructions.

After the training, participants of groups VR1 and VR2 were involved in a 10 minute 'post-training activity' in which they were asked to fill four scales:

i) the post-use SSC;

ii) the NASA-TLX (Hart and Staveland 1988) to check the workload to perform the procedure;

iii) the System Usability Scale (SUS, see: Brooke 1996) composed of a overall scale and two factors - Usability and Learnability (Borsci et al. 2015a; Borsci et al. 2009). SUS was used to assess the perceived usability of the LARTE-VBT; 
iv) the Trust in Technology Measures (TTM), developed and validated by McKnight et al. (2011). TMM was composed of an overall scale and seven factors - Reliability, Functionality, Helpfulness, Situational Normality, Structural Assurance, Faith in General Technology and Trusting Stance. This scale was used to control how much the LARTEVBT was perceived as a trustable training tool. From our set of questions we excluded the items belongs to the Helpfulness, related to the experience of the tutorial, because participants were not instructed by an automatic tutorial in the use of the LARTE application.

Trainers were instructed to measure the time spent by participants to fill these scales, and when participants spent less than 10 minutes for this activity, trainers could ask to participant to wait seated in a quiet room.

In the 'post-training test of acquired competences' (Table 1), all the participants of the three groups (VR1, VR2 and control) received a randomized list of the steps of the target procedure described with the same words used in the video explanation. Each participant was asked to reorder the steps in the correct way. Each step correctly reordered by a participant was counted as 1, and each incorrect step was counted as 0 . The score of each participant in percentage (calculated as the ratio between the sum of the correct steps and the total steps, then multiplied per 100), was used to compare the post-training knowledge of the participants about the correct execution of the steps. Moreover, only the participants who received training through the LARTE-VBT were asked to perform a 'post-training test of performance'. During the test of performance, participants were requested to perform against the time limit associated with the procedure i.e., 147 seconds. This time limit was established by asking to two trainers to perform the car service on the CAVE and on zSpace as fast as they can, without errors, for at least 5 times - only attempts without errors were counted as valid procedures. The average time of experts' performances were used to define a proficiency time limit. Participants were informed that they must perform within the proficiency time limit, otherwise after that they have finished the procedure they have to restart from the beginning. Participants had two attempts to perform below the threshold. Moreover, after each 30 second interval they could look at the video explanation of the steps if they were not able to perform, but the timer could not be stopped by the trainers. During the test, any time that the participants performed out of the procedure trainers were instructed to use this formula: "You have to perform a correct procedure, at the moment you have made a mistake, try to solve it, unless you cannot go further with procedure".

\subsection{Errors definitions and indexes of performances}

In previous literature, some researchers in the industrial field (Webel et al. 2013; Yuviler-Gavish et al. 2013; Yuviler-Gavish et al. 2011a) have discriminated in their experiments on training between two kind of errors performed by trainees after the training: 'solved/solvable' errors, i.e. errors performed but solved by operators, and 'unsolved/unsolvable', i.e. errors performed and leaved unsolved by trainees. While this approach is a useful way to discriminate among different kinds of errors we designed our experiments to avoid 'unsolvable errors'. In fact, any time participants who received virtual training (VR1 and VR2) performed an error they were informed by trainers and forced to solve the issue alone, or through the use of the virtual video instructions. We used this approach because car operators, in real service procedures, are allowed to use instruction during the service to avoid errors. In line with that, in this study, an error was identified during participants' performances when one of the following issues was noticed by trainers:

- Participants needed to use the instructions to perform correctly because: i) they do not remember how to proceed; ii) they performed wrongly one or more steps of the procedure without correcting these mistakes; iii) They forgot to perform one or more steps; iv) They 
spent more than 10 seconds, without making an action; or by attempting to perform a step without success.

- Participants do not follow correctly the procedure but they identified on their own the solution to the problem, for instance: i) participants perform wrongly or forget one or more steps of the procedure, but they immediately corrected the mistake; ii) participants missed one or more components during the procedure by losing time to recover the objects, iii) components fall down from the hand of participants and they lose time to recover these; iv) participants experience difficulties and lose time (more than 5 seconds) in handling the components.

We assessed and compared VR1 and VR 2 participants' performances in the trial after the training and in the post training test (see Table 1) by using the following seven indexes:

i) Trial errors: Number of errors performed during the trial after the training;

ii) Trial time: Time (sec) spent to perform the trial after the training;

iii) Attempts: Number of attempts needed to proficiently perform the procedure. This index was estimated as the sum of attempts performed by a participant until they perform correctly the procedure within the time limit;

iv) Errors: Overall number of errors. This index was obtained as the sum all the errors of participant performed in all the attempts;

v) Time: Overall time to perform proficiently, obtained as the sum of time (sec) spent by participants in all the attempts;

vi) Av. Time: Average time (sec) spent to perform proficiently. This index was obtained as a ratio between index $v$ and $i i i$;

vii) Av. Errors: Average number of errors - this index was obtained as a ration between index iv and iii.

Indexes $i$ and $i$ represent the first attempt of a participant to perform a procedure on the real model of car after the training. Indices $i v$ and $v$ represent the overall performance during the test with a real car. These four indexes are largely measured in literature (Webel et al. 2013; Yuviler-Gavish et al. 2013; Yuviler-Gavish et al. 2011b). Nevertheless, indexes related to the number of attempts needed to reach the proficiency (index iii) and to the average number of errors and time during the test (indexes $v i$ and vii) are only marginally considered in virtual training studies (Selvander and Åsman 2012; Sherman et al. 2005).

\subsection{Data Analysis}

Descriptive statistics and t-test analysis were used to: i) analyse and compare participants' characteristics of the three groups, ii) assess their acquisition of the competence after the training, and iii) analyse the differences between the post training performances of the VR1 and VR2 groups. Moreover, an MANOVA and a 1000 bootstrap resample linear regression analysis were applied to analyse the effect on the performances after the training of participants of VR1 and VR2, of the following factors: people characteristics and abilities, the cognitive workload they perceived to learn and execute the procedure, the trust in the use of LARTE-VBT application and the perceived usability of the training system. Finally, a Pearson's product-moment correlation coefficient and ANOVA analyses were used to observe the relationship between perceived usability and trust in the use of LARTE-VBT. The analysis was performed by IBM®SPSS 22.

\section{Results}

\subsection{Participants' characteristics}


There were no significant differences in any of the pre-measures noted among the three groups neither in terms of participant characteristics (Table 2), nor in terms of participants' previous visuospatial abilities (MRA) and preferences of learning (KLSI, see Fig. 2).

\section{TABLE 2 ABOUT HERE}

\section{FIGURE 2 ABOUT HERE}

Between the groups who received a virtual training, as we stated above, $5 \%$ of the sample was excluded due to a cybersickness event. Moreover, we also checked the cybersickness through the SSC survey before, during and after the training. No other cases of cybersickness were declared by the participants of the groups (VR1 and VR2), and no significant differences were identified in the SSC scale administrated during the phases of the experiment.

\section{Participants' acquisition of competences}

The scores of the participants in the 'post-training test of acquired competences' (Table 1) were compared through a 1000 bootstrap independent t-test (see Fig.3). The outcomes showed no significant difference between participants trained through LARTE-VBT (VR1 and VR 2 groups). Nevertheless a significant difference $(\mathrm{t}(36)=2.11 ; \mathrm{p}=.038)$ was showed among the scores of participants of the control group ( $M=42.1 ; \mathrm{SD}=20.4)$ and of VR1 group $(\mathrm{M}=58.9, \mathrm{SD}=23.2)$. Concurrently a significant differences $(\mathrm{t}(36)=2.31 ; \mathrm{p}=.025)$ was identified between control and VR2 group ( $M=63.1 ; \mathrm{SD}=31.8)$. Therefore, the experience with the LARTE VBT application resulted in a better acquisition of competence over observational training.

\section{FIGURE 3 ABOUT HERE}

\section{Performances of participant after the experiential training}

$78.8 \%$ of participants who received experiential training in the CAVE (VR1) or in the zSpace (VR2) succeed in the post-training test by performing the procedure below the threshold after one or two attempts after the training.

Fig.4 showed the percentage of success in each group to perform below the time limit.

Despite a higher percentage of people who interact with the zSpace (VR2) fail to perform the procedure within the time limit compare to trainees who interacted in a CAVE (VR1), the t-test analysis showed no significant differences in the success rate between the participants of VR1 and VR2.

\section{FIGURE 4 ABOUT HERE}

MANOVA analysis shows that characteristics of participants of VR1 and VR2 groups (e.g., age, sex, mental rotation etc.) do not affect either the trial performances or the post-training performance, although a clear tendency suggests that expert participants - i.e., more than 3 years' experience spend less time and perform fewer errors than novices during the trial. The independent t-test also showed that for both the experiential training groups there are no significant differences among participants' performances - i.e., see Table 3 , index from i to vii. 


\section{TABLE 3 ABOUT HERE}

Immediately after the training participants were requested to assess their experienced cognitive workload to learn and perform the procedure (NASA-TLX), their level of trust in the use of the LARTE-VBT as a training tool (TTM) and the perceived usability of the tool (SUS).

The overall level of cognitive workload (i.e., NASA-TLX) equals 51.27 out of 100 (min: 29.17; max: 89.01; SD: 16.30), the overall perceived usability of LARTE-VBT, measured by SUS, equals 78.88 out of 100 (min: 50 max: 100; SD: 12.32), and the level of overall trust (i.e., TTM) was 80.67 (min. 22.45; max. 100; SD: 15.69). No differences were identified between the groups (V1 and VR2) in terms of workload, usability and trust in the use of the training application.

To test the effect on people performance of the perceived cognitive walkthrough, the trust and usability in the use of LARTE-VBT tool, we perform a linear regression with an enter method and a 1000 bootstrap resample. As showed in Table 4, only small and moderate effects of NASA-TLX and TTM are significantly associated to some indexes (ii, iv-vii) of performances.

\section{TABLE 4 ABOUT HERE}

\section{Relationship between usability and trust}

Fig. 5 showed the perceived level of usability (Overall scale of SUS) and trust (Overall scale of TTM) for the virtual training groups: VR 1 (CAVE) and VR2 (zSpace). Despite there being no significant differences between the two groups, the LARTE VBT application was perceived as less usable and trustable (see Fig.5) by participants of VR2 compared to the experience of trainees in VR1 group.

\section{FIGURE 5 ABOUT HERE}

A correlation analysis was performed among SUS and TTM scale. Table 5 shows that independently if participants interacted with the LARTE-VBT tool in a CAVE or through the zSpace, there is a significant relationship among: i) the overall trust in the use of LARTE-VBT tool and its usability i.e., the usability factor of SUS; the reliability of the tool, intended as the "belief that the specific technology will consistently operate properly" (Mcknight et al. 2011) and the overall scale and the factor usability of SUS; and ii) The situational normality of TTM scale, intended as "the belief that using a specific class of technologies in a new way is normal and comfortable within a specific setting" (Mcknight et al. 2011), and the overall scale and the two factors of SUS. Concurrently, significant correlations were identified among the factors of SUS and TTM by testing the separately the two groups (Table 5). In this case, also a small though significant relationship was identified, only for the participants of VR1, between Usability factor of SUS and functionality factor of TTM intended as the expectations of trainees that by using the technology they have the capacity or capability to complete a required task (Mcknight et al. 2011).

\section{TABLE 5 ABOUT HERE}

A one way ANOVA was performed between the overall scores of TTM and the overall scores of SUS. The scores of SUS were divided in four groups in line with the SUS Curved Grading Scale (Sauro and Lewis 2012): i) Grade D (50-62.6);ii) Grade C (62.7 - 72.5); iii) Grade B (72.6-78.8); iv) Grade A (78.9-100). A significant difference was underlined between the levels of usability and the 
level of trust in the use at $\mathrm{p}<.05(\mathrm{~F}(3,38)=4.73, \mathrm{p}=.012)$. The LSD post-hoc analysis showed that there is a significant difference $(\mathrm{p}<.001)$ between the level of trust in the use of LARTE-VBT of people who rated the application as quite usable Grade $C$, and those who rated the LARTE-VBT with a good or very good level of usability (B and A). In particular, the outcomes underlined that the more the LARTE-VBT software is perceived as usable the more it is considered a trustable training system.

\section{Discussion}

Participants who were trained in a 3D environment remembered the correct order of the procedural steps significantly better than trainees who just watched twice a video explanation (see Fig. 3). In line with previous comparative analyses performed in other fields of VBT application (e.g., surgery, see: Seymour et al. 2002) the experiential activities performed in virtual environments were more effective for car maintenance skill training than observational training.

The outcomes of the post-training performance underlined that there is not a significant difference between the indexes of performances of people who interacted in the CAVE or with the zSpace (Table 3). Moreover, there are no significant differences between the two virtual training groups in terms of success or failure to perform correctly and in time (proficiency) the target procedure. Therefore, the different hardware and controllers by which people experience the VBT application did not affect the skill acquisition and execution of the procedure.

The cognitive workload perceived by participants to learn and perform the procedure, and the trust in the use of a VBT application as affecting the participants' performances (see Table 4), were as follows: i) immediately after the training (i.e., trial), the greater the cognitive workload, more time is spent by participants to perform correctly the procedure; ii) after the training, the greater the workload more errors are demonstrated and more time is spent by participants to perform proficiently the procedure; concurrently, iii) during the post-training test, the trust in the use affects the number of errors performed by participants - i.e., the greater the overall level of trust in the use of a VBT, fewer procedural errors are demonstrated by participants.

Finally, in line with previous interaction studies on websites (Cabral et al. 2005; Flavián et al. 2006), our outcomes showed that also during the interaction with a 3D virtual environment there is a relationship between the trust in the use and the perceived usability. In fact, while the perceivable trust of a VBT application is an important element for the trainees' acquisition and execution of the procedure - i.e., the greater the trust, fewer errors were demonstrated during the performance in the virtual environment - the usability affects the overall perception of the tool, thus affecting the perceived trust. Therefore, the less a VBT tool is perceived as usable the less it is considered a trustable training system.

\section{Conclusion}

The experiential training performed in virtual environments is a powerful alternative to classic video training explanations. Car manufacturers who want to invest and improve the training of car service operators have to consider that, compared to simple observation, the possibility to interact with components and experience a procedure in a 3D training application, such as the LARTE-VBT one, can enhance significantly trainees' acquisition of the procedural skills. Moreover, the hardware by which people experience the 3D environment has no impact on the training and on the posttraining performances of trainees. Therefore, portable and relatively cheap devices (i.e., compared to a full CAVE system) can be used by car industries as tools for long-distance training activities. For instance, by using multiplatform training applications, such as LARTE-VBT, car manufacturers may deliver quickly all over the world, and with a similar level of effectiveness, training on (new) service to operators who access to the training contents with different hardware: e.g., zSpace, Oculus Rift. 
Nevertheless, further comparative studies are needed to explore the impact of the device characteristics on the effectiveness of the training.

The diffusion of portable 3D devices and multiplatform VBT applications is the future main challenge for practitioners and researchers in the field of virtual reality, and several industries will benefit from the next generation of portable devices. Currently, as our results outlined, designers of VBT training application have to invest their effort in the development of multiplatform software which could be used on several devices by also focusing their attention on the usability of the interface and the functions of their VBT applications. In fact a key topic for the effectiveness of a virtual reality training experience, and for the success of these kinds of applications in the industrial field, is the subjective perception that the final end-users (i.e., operators, managers, professionals, trainers etc.) have during the training about the usability of the tool, and how much they belief that the virtual training is trustable and comparable to the real one. The present study explored the virtual training for service operators in one of the most competitive and complex industrial fields, automotive. Future studies are needed to further compare trainees' performances after virtual training preformed through different kinds of portable devices, by also comparing the effectiveness of these training with other training modalities, such as in-presence explanations and on-the-job training programmes.

\section{Acknowledgements}

This paper was completed as part of Live Augmented Reality Training Environments (LARTE) 101509 project. The authors would like to acknowledge the Technology Strategy Board for funding the work.

\section{References}

Ahlberg G et al. (2007) Proficiency-based virtual reality training significantly reduces the error rate for residents during their first 10 laparoscopic cholecystectomies The American Journal of Surgery 193:797-804 doi:http://dx.doi.org/10.1016/j.amjsurg.2006.06.050

Ai-Lim Lee E, Wong KW, Fung CC (2010) How does desktop virtual reality enhance learning outcomes? A structural equation modeling approach Computers \& Education 55:1424-1442 doi:http://dx.doi.org/10.1016/j.compedu.2010.06.006

Anastassova M, Burkhardt J-M (2009) Automotive technicians' training as a community-of-practice: Implications for the design of an augmented reality teaching aid Applied Ergonomics 40:713-721 doi:http://dx.doi.org/10.1016/j.apergo.2008.06.008

Anastassova M, Burkhardt J-M, Mégard C, Ehanno P (2005) Results from a user-centred critical incidents study for guiding future implementation of augmented reality in automotive maintenance International Journal of Industrial Ergonomics 35:67-77 doi:http://dx.doi.org/10.1016/j.ergon.2004.08.005

Anderson JR (1982) Acquisition of cognitive skill Psychological Review 89:369-406

Bandura A (1992) Observational learning. In: Squire L (ed) Encyclopedia of learning and memory. Macmillan, New York, USA,

Belardinelli C, Blümel E, Müller G, Schenk M (2008) Making the virtual more real: research at the Fraunhofer IFF Virtual Development and Training Centre Cogn Process 9:217-224 doi:10.1007/s10339-008-02160

Borsci S, Federici S, Bacci S, Gnaldi M, Bartolucci F (2015a) Assessing User Satisfaction in the Era of User Experience: Comparison of the SUS, UMUX, and UMUX-LITE as a Function of Product Experience International journal of human-computer interaction 31:484-495 doi:10.1080/10447318.2015.1064648

Borsci S, Federici S, Lauriola M (2009) On the dimensionality of the System Usability Scale: a test of alternative measurement models Cogn Process 10:193-197

Borsci S, Lawson G, Broome S (2015b) Empirical evidence, evaluation criteria and challenges for the effectiveness of virtual and mixed reality tools for training operators of car service maintenance Computers in Industry 67:17-26 doi:http://dx.doi.org/10.1016/j.compind.2014.12.002

Borsci S, Lawson G, Burgess M, Jha B (2015c) Early Prototype Assessment of a New Virtual System for Training Procedural Skills of Automotive Service Operators: LARTE Tool. In: Kurosu M (ed) HumanComputer Interaction: Users and Contexts, vol 9171. Lecture Notes in Computer Science. Springer International Publishing, pp 135-143. doi:10.1007/978-3-319-21006-3_14 
Bowman DA, Gabbard JL, Hix D (2002) A Survey of Usability Evaluation in Virtual Environments: Classification and Comparison of Methods Presence: Teleoperators and Virtual Environments 11:404424 doi:10.1162/105474602760204309

Brooke J (1996) SUS: A “quick and dirty" usability scale. In: Jordan PW, Thomas B, Weerdmeester BA, McClelland IL (eds) Usability evaluation in industry. Taylor \& Francis, London, UK, pp 189-194

Bruner J (1966) Toward a Theory of instruction. Belknap Press of Harvard University Press, Cambridge, MA

Cabral MC, Morimoto CH, Zuffo MK (2005) On the usability of gesture interfaces in virtual reality environments. Paper presented at the Proceedings of the 2005 Latin American conference on Humancomputer interaction, Cuernavaca, Mexico,

Corvaglia D Virtual Training for Manufacturing and Maintenance based on Web3D Technologies. In: 1st International Workshop on Web3D Technologies in Learning, Education and Training, Udine, Italy, 2004. pp 28-33

Dombrowski U, Engel C, Schulze S Changes and challenges in the after sales service due to the electric mobility. In: Service Operations, Logistics, and Informatics (SOLI), 2011 IEEE International Conference on, 10-12 July 2011 2011. pp 77-82. doi:10.1109/soli.2011.5986532

Eugenia Y, Nikolaos N, Despina P, Christos T Virtual reality simulators and training in laparoscopic surgery International Journal of Surgery doi:10.1016/j.ijsu.2014.11.014

Fast K, Gifford T, Yancey R Virtual training for welding. In: Mixed and Augmented Reality, 2004. ISMAR 2004. Third IEEE and ACM International Symposium on, 2-5 Nov. 2004 2004. pp 298-299. doi:10.1109/ISMAR.2004.65

Flavián C, Guinalíu M, Gurrea R (2006) The role played by perceived usability, satisfaction and consumer trust on website loyalty Information \& Management 43:1-14 doi:http://dx.doi.org/10.1016/j.im.2005.01.002

Gaiardelli P, Resta B, Martinez V, Pinto R, Albores P (2014) A classification model for product-service offerings Journal of Cleaner Production 66:507-519 doi:http://dx.doi.org/10.1016/j.jclepro.2013.11.032

Garg AX, Norman GR, Eva KW, Spero L, Sharan S (2002) Is There Any Real Virtue of Virtual Reality?: The Minor Role of Multiple Orientations in Learning Anatomy from Computers Academic Medicine 77:S97-S99

Gomes de Sá A, Zachmann G (1999) Virtual reality as a tool for verification of assembly and maintenance processes Computers \& Graphics 23:389-403 doi:http://dx.doi.org/10.1016/S0097-8493(99)00047-3

Haque S, Srinivasan S (2006) A meta-analysis of the training effectiveness of virtual reality surgical simulators Information Technology in Biomedicine, IEEE Transactions on 10:51-58 doi:10.1109/titb.2005.855529

Hart SG, Staveland LE (1988) Development of NASA-TLX (Task Load Index): Results of Empirical and Theoretical Research. In: Peter AH, Najmedin M (eds) Advances in Psychology, vol Volume 52. North-Holland, pp 139-183. doi:http://dx.doi.org/10.1016/S0166-4115(08)62386-9

ISO (1998) ISO 9241-11: 1998 Ergonomic requirements for office work with visual display terminals (VDTs) Part 11: Guidance on usability. CEN, Brussels, BE

Kolb AY, Kolb DA (2005a) The Kolb Learning Style Inventory-Version 3.12005 Technical Specifications. Hay Group Holdings, Inc., Boston

Kolb AY, Kolb DA (2005b) Learning Styles and Learning Spaces: Enhancing Experiential Learning in Higher Education Academy of Management Learning \& Education 4:193-212 doi:10.5465/amle.2005.17268566

Kolb DA (1984) Experiential Learning as the Science of Learning and Development. Prentice Hall, Englewood Cliffs, NJ

Kothari SN, Kaplan BJ, DeMaria EJ, Broderick TJ, Merrell RC (2002) Training in Laparoscopic Suturing Skills Using a New Computer-Based Virtual Reality Simulator (MIST-VR) Provides Results Comparable to Those with an Established Pelvic Trainer System Journal of Laparoendoscopic \& Advanced Surgical Techniques 12:167-173 doi:10.1089/10926420260188056

Malmsköld L, Örtengren R, Svensson L (2014) Improved Quality Output through Computer-Based Training: An Automotive Assembly Field Study Human Factors and Ergonomics in Manufacturing \& Service Industries:n/a-n/a doi:10.1002/hfm.20540

Mantovani F (2003) VR learning: Potential and challenges for the use of 3D environments in education and training. In: G. Riva, Galimberti C (eds) Towards cyberpsychology: Mind, cognitions and society in the internet age. IOS Press, Amsterdam, pp 207-226

Mantovani F, Castelnuovo G, Gaggioli A, Riva G (2003) Virtual Reality Training for Health-Care Professionals CyberPsychology \& Behavior 6:389 doi:10.1089/109493103322278772

Mavrikios D, Karabatsou V, Fragos D, Chryssolouris G (2006) A prototype virtual reality-based demonstrator for immersive and interactive simulation of welding processes International Journal of Computer Integrated Manufacturing 19:294-300 doi:10.1080/09511920500340916

Mcknight DH, Carter M, Thatcher JB, Clay PF (2011) Trust in a specific technology: An investigation of its components and measures ACM Trans Manage Inf Syst 2:1-25 doi:10.1145/1985347.1985353 
Mikropoulos T, Chalkidis A, Katsikis A, Kossivaki P (1997) Virtual realities in environmental education: the project LAKE Education and Information Technologies 2:131-142 doi:10.1023/a:1018648810609

Milgram P, Kishino F (1994) A Taxonomy of Mixed Reality Visual Displays IEICE Transactions on Information Systems E77-D:1321-1329

Mujber TS, Szecsi T, Hashmi MSJ (2004) Virtual reality applications in manufacturing process simulation Journal of Materials Processing Technology 155-156:1834-1838 doi:http://dx.doi.org/10.1016/j.jmatprotec.2004.04.401

Noor AK, Aras R (2015) Potential of multimodal and multiuser interaction with virtual holography Advances in Engineering Software 81:1-6 doi:http://dx.doi.org/10.1016/j.advengsoft.2014.10.004

Ottosson S (2002) Virtual reality in the product development process Journal of Engineering Design 13:159-172 doi:10.1080/09544820210129823

Parry G, Newnes L, Huang X (2011) Goods, Products and Services. In: Macintyre M, Parry G, Angelis J (eds) Service Design and Delivery. Service Science: Research and Innovations in the Service Economy. Springer, New York, US, pp 19-29. doi:10.1007/978-1-4419-8321-3_2

Parsons TD, Larson P, Kratz K, Thiebaux M, Bluestein B, Buckwalter JG, Rizzo AA (2004) Sex differences in mental rotation and spatial rotation in a virtual environment Neuropsychologia 42:555-562 doi:http://dx.doi.org/10.1016/j.neuropsychologia.2003.08.014

Peters M, Laeng B, Latham K, Jackson M, Zaiyouna R, Richardson C (1995) A Redrawn Vandenberg and Kuse Mental Rotations Test - Different Versions and Factors That Affect Performance Brain and Cognition 28:39-58 doi:http://dx.doi.org/10.1006/brcg.1995.1032

Renkl A (2014) Toward an Instructionally Oriented Theory of Example-Based Learning Cognitive Science 38:1-37 doi:10.1111/cogs.12086

Salanitri D, Hare C, Borsci S, Lawson G, Sharples S, Waterfield B (2015) Relationship Between Trust and Usability in Virtual Environments: An Ongoing Study. In: Kurosu M (ed) Human-Computer Interaction: Design and Evaluation, vol 9169. Lecture Notes in Computer Science. Springer International Publishing, pp 49-59. doi:10.1007/978-3-319-20901-2_5

Salzman MC, Dede C, Loftin RB, Chen J (1999) A Model for Understanding How Virtual Reality Aids Complex Conceptual Learning Presence: Teleoperators and Virtual Environments 8:293-316 doi:10.1162/105474699566242

Sauro J, Lewis JR (2012) Quantifying the User Experience: Practical statistics for user research. Morgan Kaufmann, Burlington, MA

Selvander M, Åsman P (2012) Virtual reality cataract surgery training: learning curves and concurrent validity Acta Ophthalmologica 90:412-417 doi:10.1111/j.1755-3768.2010.02028.x

Seymour NE, Gallagher AG, Roman SA, O’Brien MK, Bansal VK, Andersen DK, Satava RM (2002) Virtual Reality Training Improves Operating Room Performance: Results of a Randomized, Double-Blinded Study Annals of Surgery 236:458-464

Sharples S, Cobb S, Moody A, Wilson JR (2008) Virtual reality induced symptoms and effects (VRISE): Comparison of head mounted display (HMD), desktop and projection display systems Displays 29:5869 doi:http://dx.doi.org/10.1016/j.displa.2007.09.005

Sherman V, Feldman LS, Stanbridge D, Kazmi R, Fried GM (2005) Assessing the learning curve for the acquisition of laparoscopic skills on a virtual reality simulator Surg Endosc 19:678-682 doi:10.1007/s00464-004-8943-5

Stork A, Sevilmis N, Weber D, Gorecky D, Stahl C, Loskyll M, Michel F Enabling virtual assembly training in and beyond the automotive industry. In: Virtual Systems and Multimedia (VSMM), 2012 18th International Conference on, 2-5 Sept. 2012 2012. pp 347-352. doi:10.1109/VSMM.2012.6365944

Tang A, Owen C, Biocca F, Mou W (2003) Comparative effectiveness of augmented reality in object assembly. Paper presented at the Proceedings of the SIGCHI Conference on Human Factors in Computing Systems, Ft. Lauderdale, Florida, USA,

Valdez MT, Ferreira CM, Maciel Barbosa FP Distance education using a desktop virtual reality (VR) system. In: EAEEIE Annual Conference (EAEEIE), 2013 Proceedings of the 24th, 30-31 May 2013 2013. pp 145-150. doi:10.1109/EAEEIE.2013.6576518

Watterson JD, Beiko DT, Kuan JK, Denstedt JD (2002) A Randomized Prospective Blinded Study Validating Acquistion of Ureteroscopy Skills Using A Computer Based Virtual Reality Endourological Simulator The Journal of Urology 168:1928-1932 doi:http://dx.doi.org/10.1016/S0022-5347(05)64265-6

Webel S, Bockholt U, Engelke T, Gavish N, Olbrich M, Preusche C (2013) An augmented reality training platform for assembly and maintenance skills Robotics and Autonomous Systems 61:398-403 doi:http://dx.doi.org/10.1016/j.robot.2012.09.013

Yuviler-Gavish N, Gutiérrez T, Webel S, Rodríguez J, Peveri M, Bockholt U, Tecchia F (2013) Evaluating virtual reality and augmented reality training for industrial maintenance and assembly tasks Interactive Learning Environments:1-21 doi:10.1080/10494820.2013.815221 
Yuviler-Gavish N, Gutierrez T, Webel S, Rodriguez J, Tecchia F (2011a) Design Guidelines for the Development of Virtual Reality and Augmented Reality Training Systems for Maintenance and Assembly Tasks BIO Web of Conferences 1:29-21, 29-24 doi:10.1051/bioconf/20110100029

Yuviler-Gavish N, Yechiam E, Kallai A (2011b) Learning in multimodal training: Visual guidance can be both appealing and disadvantageous in spatial tasks International Journal of Human-Computer Studies 69:113-122 doi:http://dx.doi.org/10.1016/j.ijhcs.2010.11.005

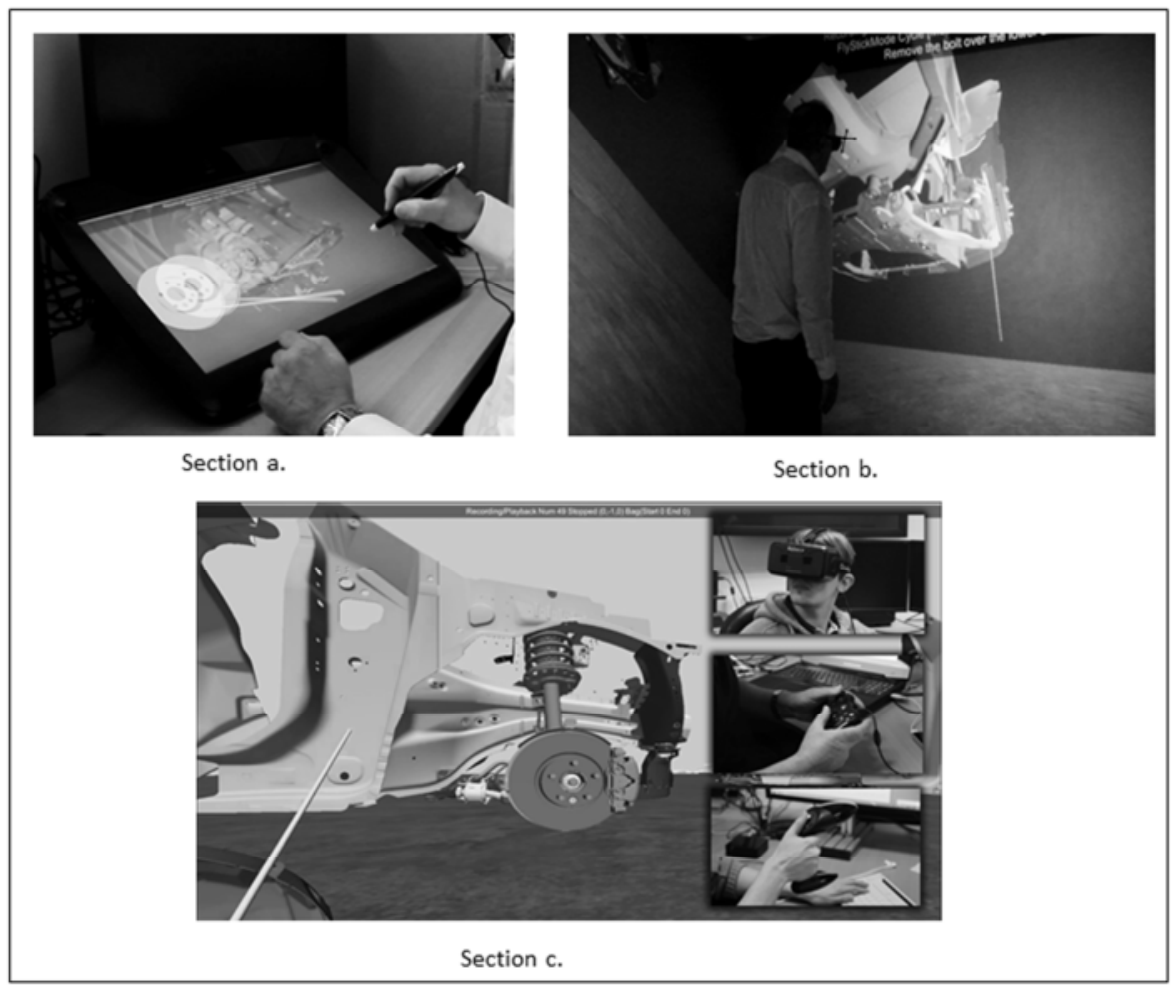

Fig.1 LARTE prototype experienced through different devices: Section a. Zspace; Section b. CAVE; Section c. Oculus Rift, and desktop devices
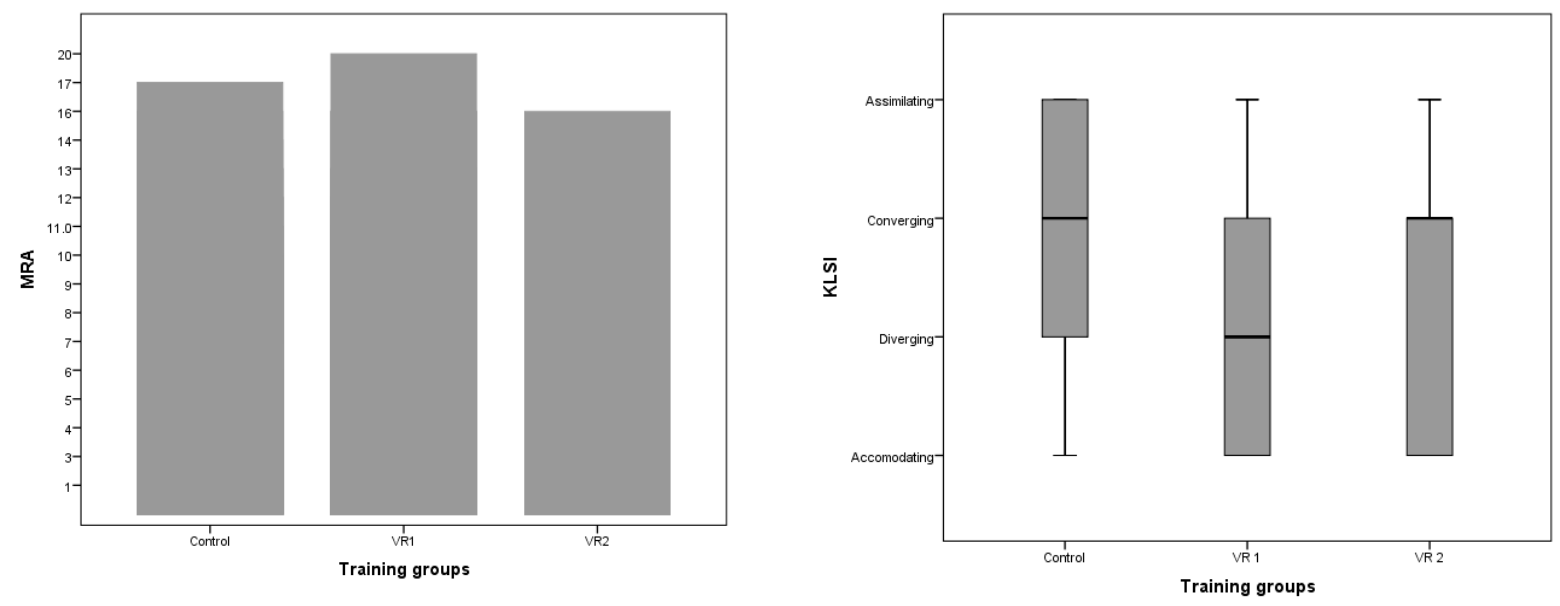

Fig. 2 Mental Rotation scores (MRA), and outcomes of learning style inventory (KLSI) for the three training groups: Control, VR 1 and VR 2. 


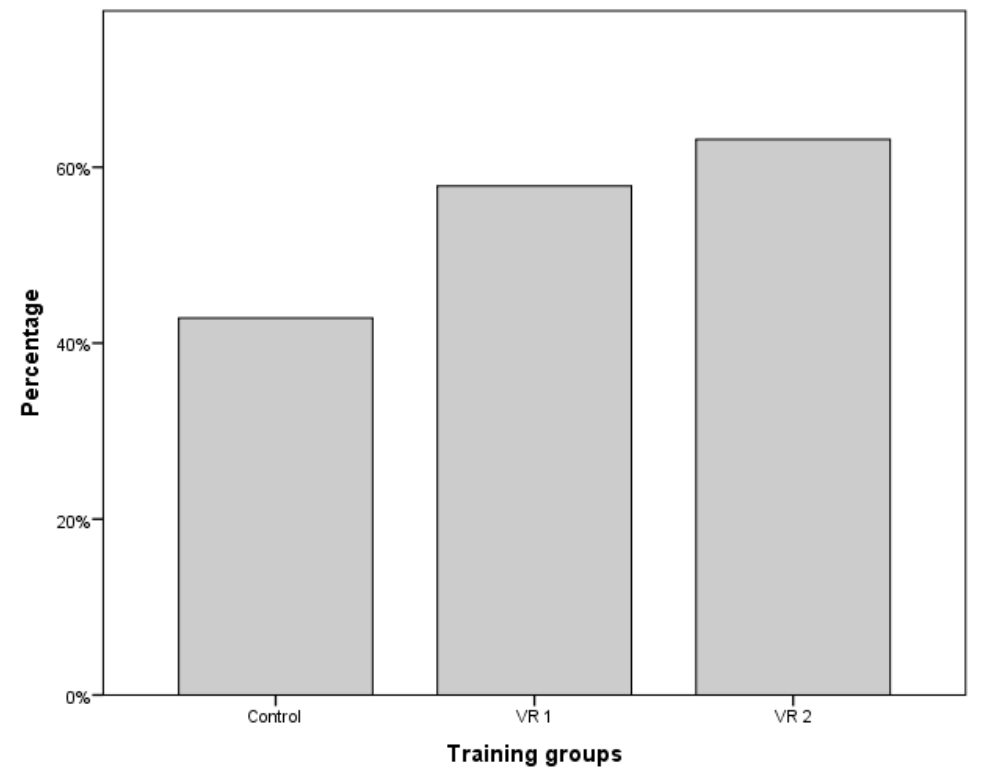

Fig. 3 Score of participants of control, VR1 and VR groups in the post-training test.

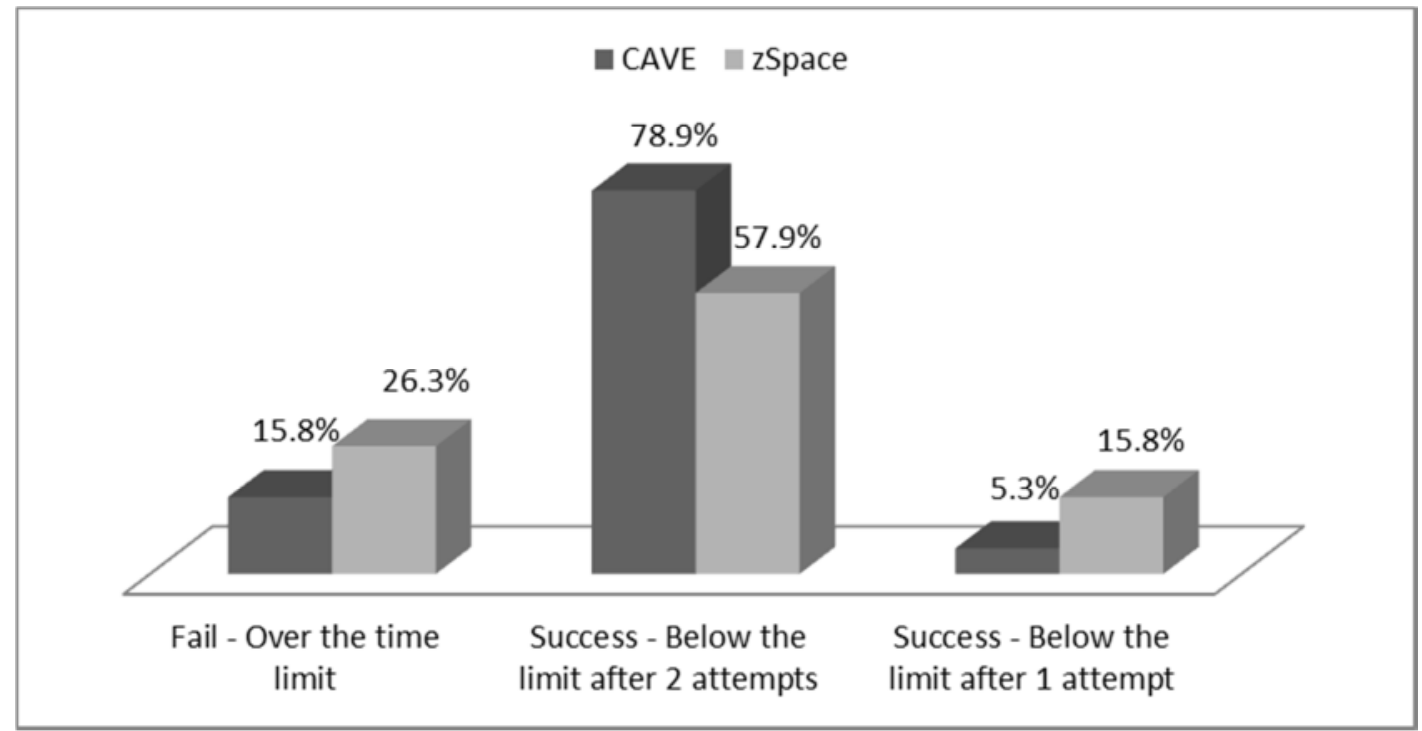

Fig. 4 Percentage of participants who perform the procedure over or below the time limit in the two groups VR1 (CAVE) and VR2 (zSpace) 


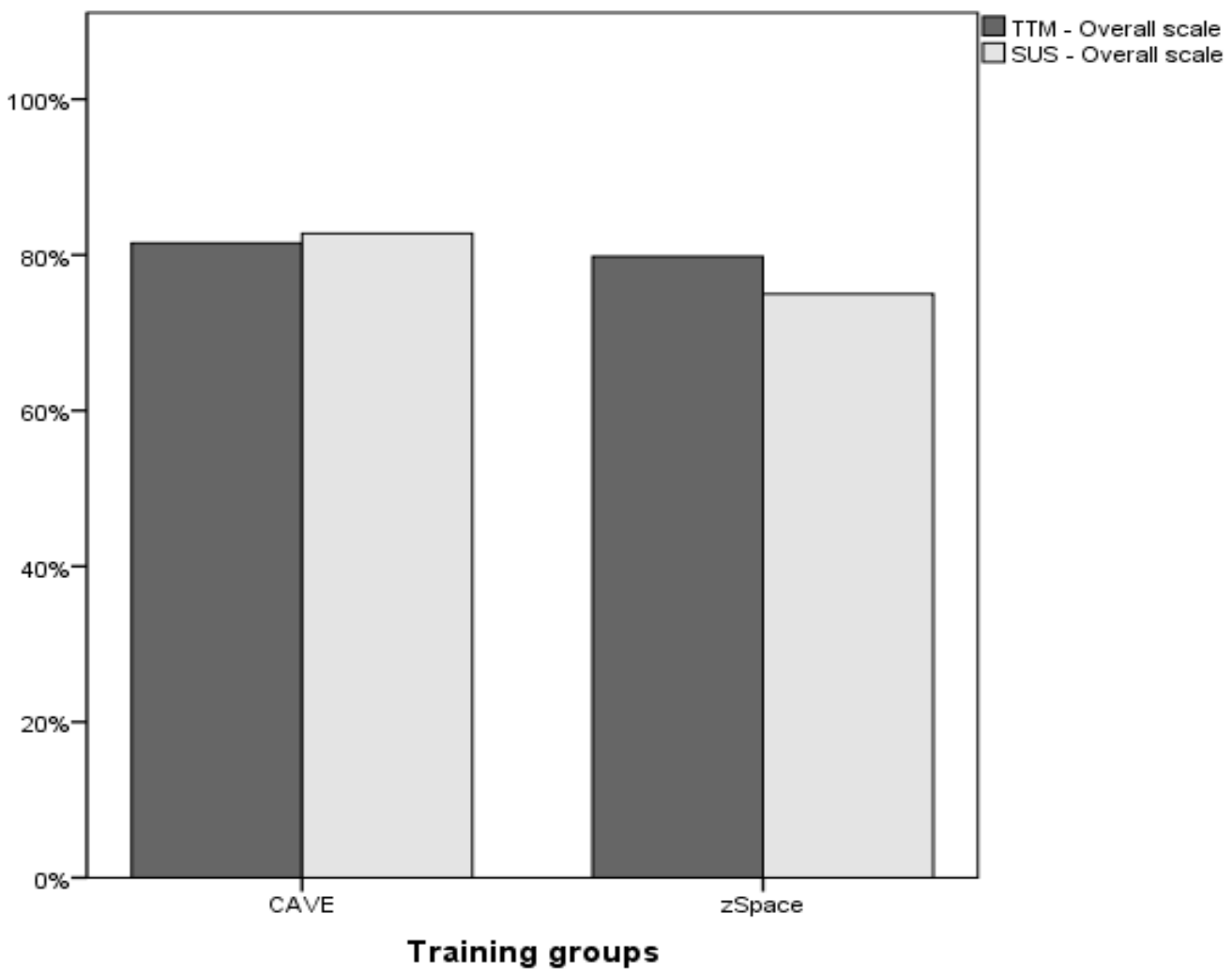

Fig. 5 Overall levels of trust in the use (TTM) and usability (SUS) perceived by participants during the interaction with the LARTE-VBT application through CAVE or zSpace.

Table 1 Study procedures and measures.

\begin{tabular}{|c|c|c|c|}
\hline \multirow{3}{*}{$\begin{array}{l}\text { TRAINING MODALITIES } \\
\text { - Groups } \\
\text { - Hardware }\end{array}$} & \multicolumn{2}{|c|}{ Experiential training } & \multirow{3}{*}{$\begin{array}{c}\text { Observational training } \\
\text { Control } \\
\text { PC desktop }\end{array}$} \\
\hline & VR1 & VR2 & \\
\hline & CAVE & zSpace & \\
\hline - Controller & $\begin{array}{l}\text { ART DTrack } \\
\text { optical wand }\end{array}$ & $\begin{array}{l}\text { Laser-based } \\
\text { stylus device }\end{array}$ & PC Mouse \\
\hline - Cost of equipment & $\begin{array}{l}\text { More than } \\
50.000 €\end{array}$ & $\begin{array}{l}\text { Less than } \\
6.000 €\end{array}$ & Less than $2.000 €$ \\
\hline \multirow[t]{2}{*}{ PRE-MEASURES } & \multicolumn{3}{|c|}{ Demographic survey } \\
\hline & \multicolumn{2}{|c|}{ SSC, MRT, KLSI } & MRT, KLSI \\
\hline $\begin{array}{l}\text { TRAINING PHASE } \\
\text { - Training on the target } \\
\text { procedure }\end{array}$ & \multicolumn{2}{|c|}{$\begin{array}{l}\text { - Explanation of LARTE- } \\
\text { VBT } \\
\text { - LARTE-VBT training } \\
\text { - Trial of the learned } \\
\text { procedure }\end{array}$} & $\begin{array}{l}\text { Watch twice a video } \\
\text { explanation }\end{array}$ \\
\hline \multicolumn{4}{|l|}{ POST-TRAINING } \\
\hline - Activity & \multicolumn{2}{|c|}{$\begin{array}{c}\text { SSC, NASA-TLX, SUS, TTM } \\
10 \text { minutes }\end{array}$} & $\begin{array}{l}\text { LDD system } \\
10 \text { minutes }\end{array}$ \\
\hline - Test of acquired competences & \multicolumn{3}{|c|}{ Reorder of a list of randomized step of target procedure } \\
\hline - Test of performance & \multicolumn{2}{|c|}{$\begin{array}{l}\text { Proficiency test of the } \\
\text { procedure }\end{array}$} & -- \\
\hline PARTICIPANTS & \multicolumn{3}{|c|}{57 volunteers } \\
\hline
\end{tabular}


Table 2 Frequency of participants' characteristics for each training group.

\begin{tabular}{|l|c|c|c|}
\cline { 2 - 4 } \multicolumn{1}{c|}{ Variables } & \multicolumn{3}{c|}{ Training groups } \\
\hline Gender & Control & VR 1 & VR 2 \\
$\quad$ Male & $42.1 \%$ & $47.3 \%$ & $36.8 \%$ \\
Age & & & \\
$\quad$ From 18 to 25 & $15.8 \%$ & $31.4 \%$ & $31.4 \%$ \\
$\quad$ From 26 to 35 & $47.3 \%$ & $26.4 \%$ & $26.4 \%$ \\
From 36 to 45 & $15.8 \%$ & $21.1 \%$ & $15.8 \%$ \\
More than 46 & $21.1 \%$ & $21.1 \%$ & $26.4 \%$ \\
Education & & & \\
Less than college & $15.8 \%$ & $26.4 \%$ & $21.1 \%$ \\
From collage to master & $57.8 \%$ & $63.1 \%$ & $57.8 \%$ \\
$\quad$ More than master & $26.4 \%$ & $10.5 \%$ & $21.1 \%$ \\
Experience in car service or similar & & & \\
$\quad$ From none to less than 1 years & $57.8 \%$ & $63.1 \%$ & $52.7 \%$ \\
$\quad$ More than 2, less than 3 years & $26.4 \%$ & $26.4 \%$ & $36.8 \%$ \\
$\quad$ More than 3 years & $15.8 \%$ & $10.5 \%$ & $10.5 \%$ \\
Previous experience with VR tools & & & \\
$\quad$ Yes & $53.1 \%$ & $52.1 \%$ & $52.6 \%$ \\
Previous experience of cybersickness & & & \\
Yes & $8.2 \%$ & $10.5 \%$ & $7.2 \%$ \\
\hline
\end{tabular}

Table 3 Mean, SD and SE of performance indexes for VR1 and VR2.

\begin{tabular}{|c|c|c|c|c|c|}
\hline Phases & Index of performances & Groups and hardware & Mean & SD & SE \\
\hline \multirow[t]{4}{*}{ TRAINING } & \multirow{2}{*}{ Index i - Trial errors } & VR 1 - CAVE & 6.7368 & 3.87072 & .88800 \\
\hline & & VR 2-zSpace & 5.3158 & 2.94491 & .67561 \\
\hline & \multirow[t]{2}{*}{ Index ii - Trial time } & VR 1 - CAVE & 162.6842 & 77.97297 & 17.88823 \\
\hline & & VR $2-$ zSpace & 175.5263 & 86.14998 & 19.76416 \\
\hline \multirow[t]{10}{*}{ POST-TRAINING } & \multirow[t]{2}{*}{ Index iii - Attempts } & VR 1 - CAVE & 1.2105 & .41885 & .09609 \\
\hline & & VR 2 - zSpace & 1.1053 & .45883 & .10526 \\
\hline & \multirow[t]{2}{*}{ Index iv - Errors } & VR 1 - CAVE & 8.4737 & 4.97067 & 1.14035 \\
\hline & & VR 2 - zSpace & 6.7895 & 4.21082 & .96603 \\
\hline & \multirow[t]{2}{*}{ Index v - Time } & VR 1 - CAVE & 155.1579 & 57.58254 & 13.21034 \\
\hline & & VR 2 - zSpace & 163.7474 & 81.10449 & 18.60665 \\
\hline & \multirow[t]{2}{*}{ Index vi - Av. Time } & VR 1 - CAVE & 89.4211 & 34.03950 & 7.80920 \\
\hline & & VR 2 - zSpace & 98.0342 & 47.84034 & 10.97533 \\
\hline & \multirow[t]{2}{*}{ Index vii - Av. Errors } & VR 1 - CAVE & 4.8684 & 2.52125 & .57842 \\
\hline & & VR $2-$ zSpace & 4.1053 & 2.72631 & .62546 \\
\hline
\end{tabular}


